\title{
The psychiatrist's response to imminent violence - have clinical practice guidelines improved practice?
}

\author{
"How is it possible to expect mankind will take advice, when \\ they will not so much as take a warning" \\ Jonathan Swift, Thoughts on Various Subjects (1711) \\ "There are some things you learn best in calm, and some in \\ storm" \\ Willa Sibert Cather, The Song of the Lark (1915)
}

It is generally accepted that violence is increasing in society and recent reports have confirmed this, recording a doubling of violent offences (Office for National Statistics, 1996). It is likely that this trend reflects changes in social structure, in particular increased poverty in large sections of the community, gaps in the distribution of wealth and social exclusion. Politicians point the finger towards such diverse social activities as substance use and rap music, and respond to the problem's complex aetiology by adding to the number of police officers on the streets, increasing the legal consequences of violent activity, pushing up sentencing tariffs and increasing prison populations.

Since the move to care for psychiatric patients in the community began in the 1980s, there has been an increasing pressure on psychiatry and its associated professions to predict and manage the risks of violent behaviour that psychiatric patients pose to their community. The 'dangerousness' associated with a particular individual is complex and might be influenced by many factors, only some of which may be predictable or manageable. The psychiatrist's ability to predict violence has been challenged, and the implications in terms of human rights mean that the protectionist role in which psychiatrists find themselves might be one to which they are not best suited (Faulk, 1988).

When mental illness was treated in large psychiatric hospitals, complaints and ultimately critical enquiries into the cruel and dehumanising nature of the care delivered led to the demise of these institutions and hence, the development of community-orientated services (Martin, 1984). In the context of the move from institution to community, it was inevitable that concerns would appear around the ability of community psychiatry to provide safe custody, public protection and continuity of care (Grounds, 1995). Much of this concern has focused on the danger posed by mentally ill individuals on members of the public. A number of incidents took place throughout the 1990s, and the public inquiries that followed have tended to draw the conclusions that services have not learned from similar previous episodes, and the expected improvement in systems to reduce and manage risk have not been put in place. Politicians have responded to society's concerns by altering the powers of the Mental Health Acts, the implications of which, at least for the moment, are unclear.
Professionals working in health and social care are also at risk of violence. Indeed, there is considerable evidence to suggest that nurses, doctors and social workers all carry an increased risk of violence compared with the general population. Some researchers have suggested that National Health Service (NHS) staff have a 1 in 200 risk of major injury through wounding at work, compared with the general public's risk of 1 in 5300 in males and 1 in 25000 in females (Rowett \& Breakwell, 1992). In social work, it has been reported that as many as one in four social workers have been involved in a violent incident (Rowett, 1986). Similar results have been found in general practice and psychiatry, with some researchers finding an associated rate of post-traumatic stress disorder of $9 \%$ among staff following violent attacks by patients in American psychiatric units. In 1987, the Health and Safety Advisory Committee reported that violence in health care settings was commonplace, with specific areas such as accident and emergency departments, psychiatric and community care services carrying the highest risk. They concluded that there was an urgent need for employers to address this issue by improving the work environment, making appropriate training available for all staff and ensuring that debriefing and post-incident counselling services were available (Health and Safety Advisory Committee, 1987). The issue has received media attention whenever a further serious incident involving a health care worker has occurred.

Again, public inquiries have followed the most tragic incidents (Spokes, 1988; Blom-Cooper et al, 1995) and all have led to broadly similar conclusions - that these episodes are to some extent preventable and that comprehensive systems of care and risk management might prevent the apparent lapses of care that have often been associated with these tragedies.

It was in this context that the Royal College of Psychiatrists (1998) produced its first clinical practice guideline, entitled Management of Imminent Violence. This guideline was the first of a series to be produced by the College to support clinical practice in a culture of evidence-based medicine. The management of violence was identified as a priority in a survey of some 1700 people who were involved in mental health care delivery as service users, providers or commissioners (Palmer, 1996). The guideline aimed to review the evidence on violence management to determine whether there was a solid research base to support clinical guidance. Its authors recommended that the guideline be used in association with the latest Health and Safety Advisory Committee (1997) guidance and the Royal College of Psychiatrists' council report on the design of psychiatric facilities (Royal College of Psychiatrists, 1998). 


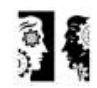

editorials
Unfortunately, under all of the key headings agreed by the multi-disciplinary expert review group (environment, use of restraint or seclusion, use of medication and short-term prediction of violence), the review of the quantitative research revealed a limited evidence base. It was therefore not possible to draw strong evidencebased conclusions. The review group also considered evidence from national guidance documents as well as discussion groups involving nurses, carers and service users that informed the content of the final good practice guideline document. There was an acknowledgement that the lack of strong research evidence was a concern. However, lessons were learned that would help direct future research studies in a field with the aim of enhancing the evidence base for future guidance revisions. It was strongly recommended that the evidence be reviewed and the document revised in light of this developing evidence base in 5 years' time. The guideline was widely disseminated, and a check-list to evaluate the extent of implementation was included.

It is time to review the impact of this guideline. In the intervening 5 years, psychiatric practice would appear to have come under the spotlight even more with regard to risk assessment. New mental health legislation makes the psychiatrist more responsible than ever before with regard to violent acts. Crucially, this responsibility now encompasses a growing population including patients who are in remission and those with personality disorders. The concept of 'clinical governance' has put more responsibility on NHS Trust Executives and Boards to take clinical risk seriously. Health departments in Westminster and the devolved administrations have expected NHS Trusts to meet rigorous clinical risk management standards and hold them accountable should they fail to meet them. Unfortunately, the strong impression within the NHS remains that many psychiatrists and general practitioner trainees working in psychiatric placements continue to practise without basic aggression management training and still work in unsafe buildings that fail to meet Health and Safety Advisory Committee standards. Simple systems to protect staff are often inadequately administered by overstretched managers. Reporting systems continue to pick up only the most serious of incidents and staff continue to deal with the trauma experienced at work without adequate post-incident counselling or support.

It is essential that, in reviewing the guideline, we address the real questions. Have we learned the lessons of the past? Has the delivery of a clinical practice guideline actually improved our practice? A national audit of the implementation of the guideline - perhaps through the approval process - would clarify just how much impact there has been on practice. A revised guideline should be given more weight and its implementation more importance in terms of accreditation. Such an approach would increase the likelihood of achieving improved practice, and would validate the process of creating clinical practice guidelines in the future.

\section{Declaration of interest}

None.

\section{References}

BLOM-COOPER, L., HALLY, H. \& MURPHY, E. (1995) The Falling Shadow. One Patient's Mental Health Care 19781993. London: Duckworth

FAULK, M. (1988) Dangerousness. In Basic Forensic Psychiatry. pp. 274-276. Oxford: Blackwell.

GROUNDS, A. (1995) Risk assessment and management in clinical context. In Psychiatric Patient Violence Risk and Response (Ed. J. Crichton). pp. 43-59. London: Duckworth.

HEALTH AND SAFETY ADVISORY

COMMITTEE (1987) Violence to Staff.

DHSS Advisory Committee on Violence to Staff report. London: HMSO

MARTIN, J. P. (1984) Hospitals in Trouble. Oxford: Blackwell.

OFFICE FOR NATIONAL STATISTICS

(1996) Notifiable Offences Recorded by Police: England and Wales (abstract of

Brian A. Kidd Consultant Psychiatrist and Clinical Senior Lecturer in the Psychiatry of Addiction, University of Dundee, Ninewells Hospital, Dundee DD1 1LB. E-mail: brian.kidd@tpct.scot.nhs.uk. statistics). London: Office for National Statistics.

PALMER, C. (1996) Clinical practice guidelines: the priorities. Psychiatric Bulletin, 20, 40-42.

ROWETT, C. (1986) Violence in Social Work. Cambridge: Institute of Criminology.

— \& BREAKWELL, G. (1992) Managing Violence atWork. Windsor: Nelson.

ROYAL COLLEGE OF PSYCHIATRISTS (1998) Management of Imminent Violence. Clinical Practice Guidelines to Support Mental Health Services (Occasional Paper OP4). London: Royal College of Psychiatrists.

SPOKES, J. (1988) Report of the Committee of Inquiry into the Care and Aftercare of Miss Sharon Campbell.

London: HMSO.

Clinical Senior Lecturer in the 